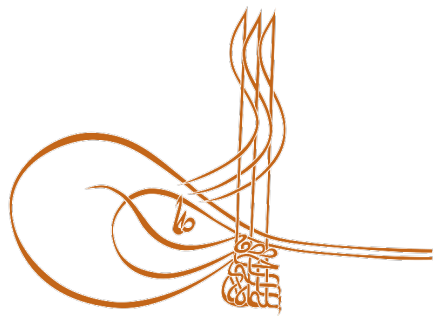

www.turkishstudies.net/language
Turkish Studies - Language and Literature

eISSN: $2667-5641$

Research Article / Araștırma Makalesi

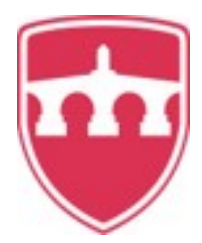

INTERNATIONAL

BALKAN

UNIVERSITY

Sponsored by IBU

\title{
Türkçenin Söz Varlığını Belirlemede Derlem Dilbilim Uygulamaları
}

Corpus Linguistics Applications in Determining the Vocabulary of Turkish

\section{Bülent Özkan ${ }^{*}$}

\begin{abstract}
This study aims to introduce the projects which have been carried out since 2007 on the basis of Turkish lexicon corpus. After the completion of the first doctoral thesis applying corpus linguistics methods and techniques in 2007 which is titled "Co-occurrence and collocations of adverbs with verbs in Turkish", further corpus-based studies on different word types in Turkey Turkish have been conducted on the basis of lexicography. Most of these studies have been completed as national research projects supported by TÜBITTAK. Among these studies, there are also those supported by scientific research projects units of universities. The central theme of all these projects was Turkey Turkish lexicon. The first of the projects to be introduced in this sense is the research project on the co-occurrence and collocations of adjectives as lexical units in Turkey Turkish. The other project is "Corpus Control and Corpus Based Dictionary of Verbs in Turkish Vocabulary". Another grammatical category that is the subject of the study conducted on the created corpus is verbals in Turkey Turkish. The last theme consisted the research is the ongoing study of nouns in Turkey Turkish lexicon. On the other hand, as a number of special field corpora, studies on children's literature and ophthalmology can also be listed in this axis. Double reduplication in Turkey Turkish and slang lexicon have also taken their place in the literature as elements of lexicon that have been determined with corpus-based studies. In summary, adverbs, verbs, adjectives, nouns and verbs in Turkish have been presented as word types through corpora; the Turkish lexicon of children's writing and ophthalmology terms have been clarified with the related method; slang lexicon and double reduplication were determined in terms of their use in Turkish. In this sense, another project is a national research project titled "Real Life Based School Dictionary Applications".
\end{abstract}

Structured Abstract: Introduction: Today's language/linguistic research has been conducted on platforms based on database applications that are arranged in an appropriate format allowing to describe the language by giving answers to research questions about the language with the query results (Özkan, 2013). Along with the advances in computer sciences, the existence of large corpora and emerging technologies in line with these corpora have made the description of language based on data-driven approaches quite valid when compared to those studies based on personal choices and intuition (Tahiroğlu, 2006).

Although corpus based studies in the West date back to the past, they continue to show rapid development as a method in in literature, lexicology, dialect studies, language teaching and grammar since the

*Prof. Dr., Mersin Üniversitesi, Eğitim Fakültesi, Türkçe Eğitimi Bölümü, Türkçe Eğitimi.

Prof. Dr., Mersin University, Education Faculty, Turkish Language Teaching Department, Turkish Language Education. ORCID 0000-0002-4319-7582

ozkanbulent@gmail.com

Cite as/ Atıf: Özkan, B. (2020). Türkçenin söz varlığını belirlemede derlem dilbilim uygulamaları, Turkish Studies -

Language, 15(1), 341-354. https://dx.doi.org/10.29228/TurkishStudies.41460

Received/Geliş: 22 January/Ocak 2020

Accepted/Kabul: 24 March/Mart 2020

Checked by plagiarism software

Copyright à INTAC LTD, Turkey 
early 1960s. Today, it is observed that the studies focused on corpus are especially concentrated in lexicography, language teaching and grammar.

In the dictionary making studies up until now, approaches such as collecting samples, relying on personal information and creating indexes were observed. When we look at the today's lexicology studies, it is clearly observed that these approaches have been replaced by a number of new methods and approaches in the axis of information technologies. Information technologies are widely used today in the creation of both general-purpose and special-purpose dictionaries such as idioms and term dictionaries (Özkan, 2013).

Today, with the sound corpora compiled from natural written and spoken language data with appropriate theories and practices have contributed substantially to the field in terms of including 'real time' linguistic data isolated from intuitive samples and secondary data (Özkan, 2010). Corpus-based studies put forward to determine Turkish lexicon have content beyond creating a corpus based on intuition and secondary data. Considering the areas where corpora are used practically, lexicology studies are the foremost among these study areas.

\section{Aim}

This study aims to introduce the projects which have been carried out since 2007 on the basis of corpus on Turkey Turkish lexicon. Most of these studies have been completed as national research projects supported by TÜBITAK. Among these studies, there are also those supported by scientific research projects units of universities. The central theme of all these projects was Turkish lexicon.

\section{Subject and Scope of the Study}

Brief introductions of the projects ${ }^{1}$ carried out both by the support of TUBITAK as national projects ${ }^{2}$ and those institutionally supported will be introduced within the scope of this study:

- Collocation of Adjectives in Turkey Turkish Vocabulary -A Corpus Based Application-

- Corpus Control and Corpus Based Dictionary of Verbs in Turkish Vocabulary

- Digitizing of Turkey Turkish Collocation Dictionary

- Verbal in Turkey Turkish

- Lexical Nouns in Turkey Turkish

- Turkish Child Literature Corpus as a Specialized Corpus and Further Applications for Turkish Child Literature

- Double Reduplication in Turkey Turkish -A Corpus Based Application

- Slang in Turkish Literature - A Corpus Based Application-

- Real Life Based School Dictionary's Applications

\section{Method}

Although the so-called "principles and methods of linguistics" have been used for the method dimension of the studies carried out on the Turkish lexicon so far, these principles and methods are based on descriptive and relational research patterns. In this sense, corpus linguistics methods are descriptive as a research method trying to determine the existing as is, and they are relational methods since cause-effect relationships cannot be established and since not being able to perform or to be able to perform change and control partially due to its nature or practical reasons (Erkuş, 2009; Karasar, 2009; Büyüköztürk et al., 2010). On the other hand, corpus linguistics has to be based on data collection methods, techniques and tools (Erkuş, 2009). In line with this, the methods and techniques offered by corpus linguistics have been used in the projects that are introduced in the scope of this study.

\section{Conclusion}

As it is included in the content, up to now, within the framework of linguistic methods and practices, studies on the corpus control of 11.320 lexical adjectives and 6.441 lexical unit verbs, corpus based dictionary

\footnotetext{
${ }^{1}$ Literature similarity stems from the fact that all of the studies promoted belong to the author.

${ }^{2}$ Some of these projects are supported by Tübitak with the project numbers: 109K104, 109K516, 111K332, 112K479, 114R033, 118K019. I thank Tübitak for their support.
} 
and corpus consisting of verbals were conducted. An ongoing study of lexical nouns in Turkey Turkish is another project presented in the study. On the other hand, lexicon on children's literature and ophthalmology through a number of special field corpora was also determined. In addition, projects of double reduplication and slang lexicon of Turkey Turkish were also presented in the scope of the study.

In summary, word types of adverbs, verbs, adjectives, nouns and verbals are presented as lexicon of Turkey Turkish and children's literature and ophthalmology terms, slang lexicon and double reduplication structure uses in Turkey Turkish were also determined through the use of corpora. In addition, ongoing project of Real Life Based School Dictionary Applications containing approximately 35,000 lexicon units have been introduced.

Key Words: Turkish Language Teaching, Lexicon, Dictionary, Turkish, Corpus Linguistics

Öz: Bu çalışma 2007 yılından bu yana Türkçenin söz varlığı üzerine derlem tabanlı olarak yürütülen projeleri alanyazına tanıtmayı amaçlamaktadır. 2007 yılında derlem dilbilim yöntem ve teknikleri kullanılarak ortaya koyulan ilk bilimsel çalışma olan Türkiye Türkçesinde Belirteçlerin Fiillerle Birliktelik Kullanımları ve Eşdizimliliği başlıklı doktora tezinin ardından Türkçede farklı sözcük türlerine yönelik sözlükbilim temelinde başkaca derlem tabanlı çalışmalar da yürütülmüştür. Söz konusu çalışmaların büyük bir kısmı TÜBİTAK tarafından desteklenen ulusal araştırma projeleri olarak tamamlanmıştır. $\mathrm{Bu}$ çalışmalar arasından üniversitelerin bilimsel araştırma projeleri birimlerince desteklenenler de vardır. Yürütülen tüm bu projelerin ana eksenini Türkçenin söz varlığı oluşturmuştur. Bu anlamda tanıtılacak olan projelerden ilki Türkçede sözlükbirimsel sıfatların birliktelik kullanımları ve eşdizimliliklerini konu alan araştırma projesidir. Diğeri ise yine, Türkçede sözlükbirimsel olarak tanımlı fiillerin derlem denetimi ve derlem tabanlı sözlügüdür. Oluşturulan derlemler üzerinden araştırma konusu yapılan diğer bir dilbilgisel kategori ise Türkiye Türkçesinde fiilimsilerdir. Araştırma konusu yapılan ana eksenin son halkasını hâlen devam etmekte olan Türkiye Türkçesinde sözlükbirimsel adlar oluşturmaktadır. Öte yandan birtakım özel alan derlemleri olarak yine söz varlığını belirlemek amacıyla çocuk yazını ve göz bilimi (oftalmoloji) üzerine yürütülen çalışmalar da bu eksende sıralanabilir. Türkçede ikili tekrarlar ve argo söz varlığı da derleme dayalı çalışmalarla bugün için ortaya koyulmuş söz varlığı unsurları olarak alanyazında yerini almıştır. Özetle, derlemler üzerinden Türkçede belirteçler, fiiller, sıfatlar, adlar ve fiilimsiler birer sözcük türü olarak ortaya koyulmuş; Türk çocuk yazınının söz varlığ 1 ve gözbilim terimleri ilgili yöntemle açıklığa kavuşturulmuş; argo söz varlığı ve ikili tekrar yapıları Türkçedeki kullanımları açısından belirlenmiştir. Bu anlamda, diğer bir proje ise Gerçek Yaşam Temelli Okul Sözlüğü Uygulamaları başlıklı ulusal araştırma projesidir.

Anahtar Kelimeler: Türkçe Öğretimi, Söz Varlığı, Sözlük, Türkçe, Derlem Dilbilim

\section{Giriș}

Günümüz dil/dilbilim araştırmaları, araştırma nesnesi olan dili araştırma sorularına bağlı olarak sorgulanabilen ve sorgu sonuçlarından yola çıkarak dil üzerine betimlemeler yapılabilir biçimde düzenlenmiş veri tabanı uygulamalarına dayalı platformlarda yürütülmektedir (Özkan, 2013). Bilgisayar bilimlerindeki gelişmeler, geniş hacimli derlemlerin oluşturulmuş olması ve buna bağlı olarak gelişen yeni teknolojiler, kişisel tercihlere dayalı ve sezgisel nitelikli çalışmalarla kıyaslandığında, dilin betimlenmesinde veriye dayalı yaklaşımları bugün için oldukça geçerli kılmıştır (Tahiroğlu, 2006).

Batıda derlem-tabanlı araştırmalar, her ne kadar daha eskiye dayansa da, 1960'lı yılların başlarından bu yana edebiyat, sözlükbilim, ăğz (diyalekt) çalışmaları, dil ögretimi ve dilbilgisinde bir yöntem olarak hızlı bir gelişim göstererek devam etmektedir. Günümüzde ise, derlem odaklı çalışmaların özellikle sözlükbilim, dil öğretimi ve dilbilgisi alanlarında yog $\square$ unlas $\square \operatorname{tıg} \square 1$ gözlemlenmektedir.

Bugüne kadarki sözlük oluşturma çalışmalarında tanık toplamak, kişisel bilgilere dayanmak, fiş indeksi oluşturmak vb. sözlük yazma yaklaşımlarının varlığı gözlemlenmektedir. Sözlük bilimi 
çalışmalarının bugününe baktığımızda ise bu yaklaşımların yerlerini bilişim teknolojilerinin ekseninde yeni birtakım yöntem ve yaklaşımlara bıraktığı açıç̧a gözlenir. Gerek genel amaçlı gerekse deyimler sözlüğü ya da terim sözlükleri gibi özel amaçlı sözlüklerin ortaya koyulmasında günümüzde bilişi̇im teknolojilerinden büyük ölçüde yararlanılmaktadır (Özkan, 2013).

Bugün $\operatorname{dog} \square$ al ortamlardan yazılı ve sözlü olarak derlenen dil verileriyle kendine özgü kuram ve uygulamalarla ortaya koyulan sag $\square$ lam kurulus $\square$ lu derlemler, özellikle dil ög $\square$ renimi ve $\ddot{o g} \square$ retimi alanında sezgisel örnekçelerden ve ikincil verilerden yalıtılmıs $\square$ 'gerçek zamanlı' dilsel verileri içermesi bakımından alana büyük katkılar sag $\square$ lamaktadır (Özkan, 2010).

Türkçenin söz varlığını belirlemek amacıyla ortaya koyulan derlem tabanlı çalışmalar Türkçe için bu anlamda derlem oluşturmanın ötesinde bir içeriğe sahiptir. Derlemlerin pratik olarak kullanıldığı alanlar göz önünde bulundurulduğunda sözlükbilim çalışmalarının bu çalışma alanları arasında en önde geldiği gözlemlenir.

\section{Amaç}

Bu çalışmanın amacı 2007 yılından bu yana Türkçenin söz varlığ üzerine yürütülen derlem tabanlı projeleri alanyazına tanıtmaktır. Söz konusu çalışmaların büyük bir kısmı TÜBİTAK tarafından desteklenen ulusal araştırma projeleri olarak tamamlanmıştır. Bu çalışmalar arasından üniversitelerin bilimsel araştırma projeleri birimlerince desteklenenler de vardır. Yürütülen tüm bu projelerin ana eksenini Türkçenin söz varlığı oluşturmuştur.

\section{Konu ve Kapsam}

Bugüne kadar gerek ulusal proje olarak TÜBİTAK tarafindan gerekse de kurumsal olarak desteklenerek yürütülmüş olan:

- Türkiye Türkçesi Söz Varlı̆̆ında Sıfatların Eşdizimliliği -Derlem tabanlı Bir Uygulama-

- Türkiye Türkçesinde Fiillerin Derlem Denetimi ve Derlem Tabanlı Sözlüğü

- “Türkiye Türkçesi Eşdizim Sözlüğ̈̈"nün Sayısallaştırılması

- Türkiye Türkçesinde Fiilimsiler

- Türkiye Türkçesinde Sözlükbirimsel Adlar

- Bir Özel Alan Derlemi Olarak "Türk Çocuk Yazını Derlemi” ve Türk Çocuk Yazını Üzerine İleri Uygulamalar

- Türkiye Türkçesinde İkili Tekrarlar -Derlem Tabanlı Bir Uygulama-

- Türk Yazin Dilinde Argo -Derlem Tabanl Bir Uygulama-

- Gerçek Yaşam Temelli Okul Sözlüğü Uygulamaları

başlıklı projelerin ${ }^{3}$ kısa tanıtımları bu çalışma kapsamında ele alınmıştır. ${ }^{4}$

\section{Yöntem}

Şimdiye kadar Türkçenin söz varlığı üzerine yürütülmüş çalışmaların yöntem boyutu için her ne kadar "derlem dilbilimin ilke ve yöntemleri” adlandırması yapılmaktaysa da gerçekte söz konusu ilke ve yöntemler betimsel ve ilişkisel araştırma desenlerine dayanmaktadır.

$\mathrm{Bu}$ anlamda derlem dilbilim yöntemleri olanı olduğu gibi saptamaya çalışan bir araştırma yöntemi olarak betimsel; neden-sonuç ilişkisi kurulamayan, doğası gereği veya pratik nedenlerle değişim ve denetimin yapılamaması veya kısmen yapılabilmesi açısından da ilişkisel araştırmalar (Erkuş, 2009; Karasar, 2009; Büyüköztürk vd., 2010) olarak değerlendirilebilir. Diğer taraftan derlem dilbilim özel amaçlarla geliştirilmiş, veri toplama yöntem, teknik ve araç-gereçlere (Erkuş,

\footnotetext{
${ }^{3} \mathrm{Bu}$ projelerden bazıları: 109K104, 109K516, 111K332, 112K479, 114R033, 118K019 proje numaralarıyla Tübitak tafafından desteklenmiştir. Destekleri için Tübitak'a teşekkür ederim.

${ }^{4}$ Literatür benzerliği tanıtılan çalışmaların tamamının yazara ait olmasından kaynaklanmaktadır.
} 
2009) de dayanmak zorundadır. Bu anlamda bu çalışmanın konusunu oluşturan araştırmalarda derlem dilbilimin araştırmacılara sunduğu yöntem ve teknikler kullanılmıştır.

Söz konusu projelerin amaç, kapsam ve ulaşılan sunuçlara sırasıyla aşağıda değinilecektir:

\section{Uygulama-}

Türkiye Türkçesi Söz Varlığında Sıfatların Eşdizimliliği -Derlem tabanlı Bir

\section{[Destekleyen Kuruluş: Tübitak Sobag Proje No:109K104]}

Bir dilin temel söz varlığını derlemek sözlükbilim (lexicology) çalışmalarının ana amaçlarındandır. Sözlükbilim sadece ana dilin kullanıcıları için genel amaçlı sözlükler değil belirgin amaçlar doğrultusunda hazırlanmış özel amaçlı sözlükler (atasözleri ve deyimler sözlügü̈, terim sözlükleri, eş anlamlı sözcükler sözlüğü, zıt anlamlı sözcükler sözlüğü, eşdizim sözlüğü vb.) oluşturmakla da ilgilenir.

Bugün, Türkiye Türkçesinin söz varlı̆̆ı üzerine yapılan çalışmalar değerlendirildiğinde genel amaçlı sözlük çalışmalarının yanında özel amaçlı sözlük çalışmalarının yetersizliği ve sınırlılığı açıkça gözlemlenmektedir. Sözlükbilimde özel amaçlı çalışmaların bir ürünü olan eşdizim sözlüğ̈̈ Türkiye Türkçesinin söz varlığı çalışmalarında üzerinde durulmayan bir konu olarak karşımıza çıkmaktadır. Öte yandan, eşdizimlilik literatürde, özellikle de derlem dilbilim (corpus linguistics) alanındaki çalışmalarda ve sözlükbilimde dil öğretimi alanında önceliklerin belirlenmesi aşamasında çokça başvurulan bir yöntem olarak yerini almıştır.

$\mathrm{Bu}$ projede, Türkiye Türkçesinin söz varlığında madde başı ve madde içi olarak sözlükbirimselleştirilmiş 11.320 sıfat tanımlı sözlükbirim adlarla eşdizimlilikleri açısından derlem tabanlı bir uygulama temelinde değerlendirilmiş, Güncel Türkçe Sözlük'ün (GTS) sıfat temelli bir 'derlem denetimi' yapılmış, ana dili ve ikinci dil öğretiminde önemli bir yere sahip olan eşdizimsel yapılar Türkçe için bu eksende tespit edilmiştir. Proje bu açıdan amaç, kapsam ve yöntem olarak Türkiye Türkçesi için bir ilk olma özelliği taşımaktadır.

Bu projeyle ulaşılan sonuçlar şöyle sıralanabilir:

- Genelde dil özelde de Türkçede yoğun bir kullanıma sahip olan sıfatların dizimsel özellikleri belirlenmiştir.

- Türkçenin söz varlı̆̆ını barındıran GTS'de sıfatların anlamsal ve dizimsel bir derlemdenetimi yapılmıştır.

- Türkçede sıfat-ad ve ad-sıfat ilişkisinde kavram alanları belirlenmiştir.

- Türkçenin ana dili ve yabancı dil olarak öğretimi konusunda sıfat-ad ilişkiselliği temelinde var olan kullanım görünümleri sıklık temelli olarak belirlenmiştir.

- Türkiye Türkçesinin Eşdizim Sözlüğü için sıfat-ad birlikteliği açısından temel veriler derlenmiştir.

- Sıfatların kullanım sıklıkları ve dil öğretimindeki önceliklerinin yanında adların da sıklıkları ve dil öğretimindeki öncelikleri belirlenmiştir.

- Sözcük türü olarak GTS'de yer alan sıfatların söz varlığında adlarla ilişkisellikleri ve anlamsal özellikleri belirlenmiştir.

- Türkiye Türkçesinde sıfatlar ile ilgili devam çalışmalarında önemli ölçütte veri derlenmiş ve diğer araştırmacıların kullanımına sanal ortamda sunulmuştur.

\section{Türkiye Türkçesinde Fiillerin Derlem Denetimi ve Derlem Tabanlı Sözlüğü}

[Destekleyen Kuruluş: Tübitak - Sobag Proje No:109K516]

Bugün sözlükbilim (lexicology) uygulamaları gelişen bilişim teknolojilerine koşut olarak daha fazla sözcükbirimi daha hızlı ve güvenilir bir biçimde işleyecek yetkinliğe ulaşmıştır. Bunda 
sözlükbilimin söz konusu sözcükbirimleri ayrıntılandırmada derlem dilbilimin (corpus linguistics) ilke ve yöntemlerinden yararlanıyor olması önemli bir etkendir. Öyle ki, bugün sözlükbilim ve derlem dilbilim birbiriyle iç içe geçmiş iki ayrı dilbilim dalı durumundadır.

Sözlükbilimin ilke ve yöntemleri açısından Türkiye Türkçesinin Söz Varlığını (TTSV) barındıran sözlükler (bugüne kadar yayınlanmış olan) değerlendirildiğinde bu sözlüklerin; sözlükbirimlerin yazımsallığ tanıklarının yetersizliği ve birçok sözlükbirimin sözlükte tanıksız yer alması, sözcük türlerinin etiketlenmesindeki eksiklikler, sözlük malzemesinin gerçek zamanlı olmaması vb. nedenlerle 'genel amaçlı, ansiklopedik' sözlükler oldukları görülür.

$\mathrm{Bu}$ durumun temel nedeni Türkçe için henüz nitelikli, kapsamlı ve standartlara uygun bir derlemin oluşturulamamış olmasıdır. Doğal olarak, sözlük çalışmalarımız da derlem tabanlı (corpus based) olmaktan uzaktır. Bu açıdan sözlükbilim çalışmalarımızın derlem tabanlı uygulamaların sonuçlarını esas alan, sözlükbirimlerin ve anlamsal sıklıklarının göz önüne alındığı, gerçek zamanlı, kullanıcı temelli anlayıştan uzak bir çerçevede olduğu gözlemlenmektedir.

Projeyle bugüne kadar sözlüklerde yer alan Madde Başı ve Iç̧i Fiiller (MBİF), nitelikli kapsamlı ve standartlara uygun biçimde hazırlanmış bir derlemden yazımsallıkları, madde başı açıklamaları, tanıkları, sözcük türü olarak etiketleri açısından gerçek zamanlı olarak denetlenmiş ve MBİF'ler bu derlemden elde edilen veriler 1şı̆̆ında yeniden düzenlenmiştir.

Bu projeyle ulaşılan sonuçlar şu şekilde özetlenebilir:

- Türkiye Türkçesinde sözlükbirimsel olarak fiil tanımlı söz varlığı temsil gücü yüksek bir derlemden sıklık temelli olarak belirlenmiştir. Özellikle Türkçenin yabancı dil olarak öğretiminde fiiller açısından öncelikli söz varlığı bu çalışmayla ortaya koyulmuştur.

- Derlem denetimi sonucunda 6.374 fiilden 4.682'sinin tanığına oluşturulan derlemde rastlanmış ve söz konusu fiillerin tamamı tanıklanmıştır.

- Derlemde tanığına rastlanan 4.682 fiilden 1.539 'unun var olan tanımlanmamış diğer/yeni kullanımlarının (anlamlarının) olduğu belirlenmiştir.

- Söz konusu 6.374 fiilden 1.692'sinin derlemde tanığına rastlanmamıştır. Derlemde tanığına rastlanılmayan madde başı fiillerin genel özelliklerini eskicil olmak, özel bir alana ait olmak, argo ve/ya halk dilinden sözcükbirimler olmak gibi nedenlerle açıklamak mümkündür.

- Projeyle özel amaçlı sözlük çalışmaları (ana dili ve dil öğretimi, eşdizimlilik, eş ve yakın anlamlılık, karşıt anlamlılık vb.) açısından fiiller 'gerçek zamanlı' olarak sözlükbirimsel anlamda ortaya koyulmuş ve oluşturulan "derlem tabanlı fiil sözlüğü” kullanılarak devam çalışmalarında Türkçenin öğrenici sözlüğü gibi özel amaçlı sözlük çalışmalarında kullanılabilecek dilsel malzeme ortaya çıkarılmıştır.

- Ortaya çıkan sözlükbilimsel malzeme devam çalışmalarında diğer araştırmacıların kullanımına sanal ortamda sunulmuş, sözlükbilim çalışmalarına bu anlamda önemli katkılar sağlanmıştır (http://turkcederlem.mersin.edu.tr/fiiller/)

“Türkiye Türkçesi Eşdizim Sözlüğü”nün Sayısallaştırılması

\section{[Destekleyen Kuruluş: Tübitak - Sobag Proje No:111K332]}

Dil araştırmaları, bilişim teknolojilerinin gelişimi sonucu, diğer tüm bilim dallarında olduğu gibi, bambaşka bir yönde ilerlemektedir. Batıda on yıllar önce başlayan 'Doğal Dil İşleme' (DDİ) çalışmaları, bugün, bir mühendislik alanına dönüşmüş durumdadır. Her ne kadar Türkiye'de bu amaçla yürütülen çalışmalar son yıllarda hız kazansa da, 'bilgisayar destekli dil/dilbilim çalışmaları' olarak da adlandırılan bu alanda, oldukça güvenilir ve hızlı erişilebilir dilsel bir ortamda, özellikle sözlükbilim ve sözdizim çalışmalarında, dilin kullanım özelliklerini belirlemek, ana dili ve yabancı 
dil öğretimine yönelik sıklığı yüksek yapıları ve kullanımlarını ortaya çıkarmak, vb. amaçlarla derlem (corpus) oluşturmak ve bunu işlemek başlıca çalışma konuları olarak karşımıza çıkmaktadır.

Projenin amacı bir sözcük türü olarak Güncel Türkçe Sözlük’te (GTS) yer alan fiil, zarf, sıfat ve isim olarak tanımlı sözlük birimlerin ilişkiselliğini derlem tabanlı (corpus-based) bir uygulamayla ortaya koymaktır.

Projenin amacı doğrultusunda erişilen çıktıları şöyle sıralayabiliriz:

- GTS'de yer alan fiil, zarf, sıfat ve isimlerin söz varlığında ilişkisellikleri ve anlamsal özellikleri belirlenmiştir. GTS'de yer alan fiil, zarf, sıfat ve isimlerin derlem-denetimli bir dökümü oluşturulmuştur.

- Fiil, zarf, sıfat ve isimlerin ilişkisellikleri değerlendirilirken onların bağdaşıklık ölçütleri içerisinde gerçekleşen yapılar olarak dizgede bir arada bulunmaları esas alınmıştır. Dizimsel olarak fiil $<=>$ zarf mom sıfat $<=>$ isimlerin eşdizimlilikleri belirlenmiştir. Böylece, Türkçede fiil $<=>$ zarf mom sıfat $<=>$ isim ilişkisinde kavram alanları ortaya koyulmuştur.

- Türkçenin ana dili ve yabancı dil olarak öğretimi konusunda fiil $<=>$ zarf mom sıfat $<=>$ isim ilişkiselliği temelinde var olan kullanım görünümlerinin ortaya koyulduğu bu çalışmayla sıklık temelli olarak dizinlerde ve ayrıca genel sıklık dizinlerinde fiil $<=>$ zarf mo̊ sıfat $<=>$ isim listelenerek gösterilmiştir. Böylelikle, Türkçenin ana dili ve yabancı dil olarak öğretimi konusunda fiil $<=>$ zarf m̊m sıfat $<=>$ isim ilişkiselliği temelinde var olan kullanım görünümleri sıklık temelli olarak belirlenmiştir.

- Ayrıca, Türkiye Türkçesinde eşdizimlilik ve derlem dilbilim ile ilgili devam çalışmalarında önemli ölçütte veri yordanmış ve diğer araştırmacıların kullanımına sanal ortama sunulmuştur (http://turkcederlem.mersin.edu.tr/esdizim/).

\section{Türkiye Türkçesinde Fiilimsiler}

[Destekleyen Kuruluş: Tübitak - Sobag Proje No: 114R033]

Türkçeye anlatım gücü ve kıvraklığı kazandıran, anlatılanları kısa yoldan aktarmayı sağlayarak gereksiz tekrarları önleyen, aktarılmak istenen düşüncenin iletilmesinde kolaylık sağlayan ve sözdizimsel olarak tümceleri akıcı, kolay biçimde birbirine bağlayan fiilimsiler kullanım yoğunluğu açısından Türkçede önemli bir yer tutmaktadır.

Projenin amacı, Türkiye Türkçesinde farklı dilbilgisi terimleriyle karşılansa da genelde tüm araştırmacıların üzerinde uzlaştıkları isim fiil, sıfat fiil ve zarf fiil olarak kavramlaştırılan fiilimsi/eylemsi kategorisinde yer alan dilbilgisel yapıları, derlem dilbilimin ilke ve yöntemleriyle oluşturulmuş 35 milyon (+/-) sözcükbirim içeren bir derlemden biçimsel ve işlevsel nitelikleri ile diğer dilbilgisel görünümleri açısından bütüncül olarak araştırma konusu yapmaktır.

Bu çerçevede projenin amacını, fiilimsilerin morfolojik yapılarını, bu morfolojik yapılardan kaynağını alan işlevlerini, bunlara bağlı olarak fiilimsilerin ana dili ve yabancı dil olarak Türkçenin öğretiminde önceliklerini, bu önceliklere bağlı olarak da fiilimsilerin eşdeğerliliklerini, tabakalara (metin türleri vb.) göre dağılımlarını, dizgesel etiketlerini ve deyim/kalıp ifadelerde kullanımlarını belirlemek şeklinde açıklayabiliriz.

$\mathrm{Bu}$ anlamda projenin araştırma sorularını şu şekilde sıralayabiliriz:

- Fiilimsilerin morfolojik yapı özellikleri nasıldır?

- Fiilimsi yapılarının işlevsel nitelikleri nelerdir?

- Ana dili ve yabancı dil olarak Türkçenin öğretiminde öncelikli fiilimsi kullanımlarının yapı ve işlevleri nelerdir? 
- Fiilimsilerin işleve bağlı olarak eşdeğerlilikleri nasıldır?

- Tabakalara göre (metin türleri vb.) fiilimsilerin dağılımları nasıldır?

- Fiilimsilerin dizgesel etiketleri ve deyim/kalıp ifadelerde kullanımları nasıldır?

Yukarıda sıralanan araştırma soruları çerçevesinde araştırma konusu yapılan fiilimsilerin 35 milyon (+/-) sözcükbirim içeren bir derlemden araştırılması, onların biçimbirimsel çözümlemelerini, sıklık dizinlerini, sözbiçimlerini, bağlam içi anahtar sözcük gösterimlerini ya da bağımlı dizinlerini, birliktelik kullanımlarını ve eşdizimliliklerini beraberinde barındırır (Özkan 2013).

Şimdiye kadar fiilimsiler üzerine yürütülmüş olan çalışmalara göz attığımızda yapılan çalışmaların ya Türkçenin belirli bir kullanım alanını kapsadığını ya da sınırlı metin arşivleri aracılığıyla fiilimsilerin birtakım özelliklerini ortaya koymaya çalıştığını gözlemleriz. Ulaşılan hedefler ve beklenen çıktılar açısından bu projeyle, fiilimsiler yukarıda sıralanan araştırma soruları çerçevesinde, Türkiye Türkçesini temsil gücü yüksek bir derlem aracılığıyla değerlendirilmiştir. Öte yandan projeyle Türk lehçeleri üzerine yürütülen çok sayıda karşılaştırmalı çalışmada kullanılacak olan Türkiye Türkçesinin bütüncül bir fiilimsi topografyası ortaya koyulmuştur. Yine, araştırma sorularına çerçevesinde ortaya koyulan sonuçlar, Türkçenin öğretiminde kullanılacak olan önemli veri setleri olarak literatürde yerini almıştır. Projeyle ulaşılan çıktılar, dilbilimsel çalışmaların tüm alanlarında, hatta makineli çeviri gibi bilişim teknolojileri ile dilbilimin birleştiği alanlarda bile, işlenmiş ve yapılandırılmış veri setleri olarak kullanılma potansiyeline sahiptir (http://turkcederlem.mersin.edu.tr/fiilimsi/).

\section{Türkiye Türkçesinde Sözlükbirimsel Adlar}

[Destekleyen Kuruluş: Özel Kurum ve Kuruluşlar]

Sözlük bilim yöntem ve uygulamaları geçmişten bugüne bilişim teknolojilerine paralel olarak birtakım yenilikleri beraberinde getirmiştir. Geçmişte fişleme, sınıflandırma, yeniden yazma vb. yöntemlerle dil nesnesini kendine konu edinen sözlük bilim, günümüzde derlem (corpus) adı verilen dilsel bütünceler üzerinden araştırma nesnesine yönelmiştir. Alanyazına baktığımızda Oxford, Collins, Longman, Cambridge benzeri sözlüklerin derlem tabanlı (corpusbased) uygulamalar sonucu oluşturuldukları görülür. Öte yandan genel hatlarıyla Türkiye Türkçesinin Söz Varlı̆̆ını (TTSV) barındıran sözlüklerin derlem dilbilimin ve çağdaş sözlük bilim uygulamalarının pratiğinden uzak olduğu gözlemlenir.

Bu çerçevede projenin amacı, Türkiye Türkçesini temsil gücü yüksek bir derlemden Türkiye Türkçesinde sözlükbirimsel adların morfolojik yapı özelliklerini, gözlenen ve bağll sıklık görünümlerini, anlamsal sıklık dağılımlarını, birlikte kullanım ve eşdizimliliklerini, yeni söz (neoloji) durumlarını, derlemde yer alan tabakalara göre dağllımlarını ve deyim/kalıp ifadelerde kullanımlarını belirlemek ve bu belirlemeler 1şığında sözlükbirimsel adları yeniden yapılandırmak/sözlükbirimleştirmektir. Söz konusu proje 127 milyon sözcükbirim içeren Türkçe Sözlükbilim Araştırmaları Derlemi üzerinden yürütülmektedir.

Şimdiye kadar derlem tabanlı sözlük uygulamaları çerçevesinde Türkçenin söz varlığında sözlükbirimsel olarak tanımlı zarflar, sıfatlar, fiiller ve fiilimsiler üzerine ulusal araştırma projeleri yürütülmüştür. Bu anlamda derlem tabanlı sözlük uygulamalarında şimdiye kadar araştırma konusu yapılmayan sözcük türü olarak adlar bu projenin konusunu oluşturmaktadır.

Türkiye Türkçesi söz varlığında yoğunluklarına göre sırayalacak olursak adlar (53.451), sifatlar (12.666), fiiller (9.912), zarflar (3.312) ve diğer sözlükbirimlerle karşılaşırız (TDK, 2011). Bu sıralamada ad tanımlı sözlükbirimlerin diğer sözlükbirimlere göre oldukça yoğun olduğu gözlemlenir.

$\mathrm{Bu}$ çerçevede projenin araştırma sorularını; 
- Adların morfolojik yapı özellikleri nasıldır?

- Adların gözlenen ve bağıl sıklık görünümleri nasıldır?

- Adların anlamsal sıklık dağılımları nasıldır?

- Adların birlikte kullanım ve eşdizimlilikleri nasıldır?

- Adların yeni söz (neoloji) durumları nasıldır?

- Adların tabakalara göre dağılımları nasıldır?

- Adların deyim/kalıp ifadelerde kullanımları nasıldır? șeklinde sıralayabiliriz.

Araştırma sorularına bağlı olarak ortaya koyulacak olan sonuçlar, Türkçenin öğretiminde kullanılacak olan önemli veri setleri olarak literatürde yerini alacaktır.

Projeyle ulaşılacak olan çıktılar dilbilimsel çalışmaların tüm alanlarında hatta makineli çeviri gibi bilişim teknolojileri ile dilbilimin birleştiği alanlarda bile işlenmiş ve yapılandırılmış veri setleri olarak kullanılma potansiyeline sahiptir. Ayrıca proje yöntem bilimsel anlamda yeni ve farklı yaklaşımlar sunmasıyla Türkçe üzerine yürütülecek olan devam çalışmalarında ortaya koyduğu yöntem ve sonuçlarla bu anlamda önemli katkılar sağlayacaktır. Bunun yanı sıra "Türkçenin Derlem Tabanlı Sözlüğü”nün oluşturulması aşamasına fiil, zarf ve sıfatlara adlar da eklenmiş olacaktır.

\section{Bir Özel Alan Derlemi Olarak “Türk Çocuk Yazını Derlemi” ve Türk Çocuk Yazını Üzerine İleri Uygulamalar}

[Destekleyen Kuruluş: Tübitak - Sobag Proje No: 112K479]

Derlem (corpus), dilbilimde bir dili belirgin dilbilimsel ölçütlere göre örneklemek amacıyla o dile ait yazılı ve sözlü metinlerden seçilerek belirli standartlara göre düzenlemiş metin parçalarının bütünü (McEnery vd., 2006) olarak tanımlanabilir.

Bir derlem için gerekli ölçütlerin başında ise oluşturulduğu dili örnekleyebilmesi (sampling) ve o dili temsil gücü (representativeness) gelir. Bunun yanı sıra belirli bir sinıra (finite size) sahip olmas1 ya da olmamas1 (dynamic size), bilgisayarlarca okunabilir (machine-readable) bir yapıda hedef dili betimlemede ölçünlü bir başvuru kaynă̆g (standart reference) niteliği taşıması bir derlemin oluşturulmasında önemli ölçütlerdendir (McEnery vd. 2006).

Literatürde var olan biçimiyle derlemler içlemleriyle ve amaçl1lıklarıyla koşut olarak çeşitlilik gösterir. Oluşturulan derlemler araştırma sorusuna bağlı olarak geliştirilmektedir. Örneğin: yazılı ve/ya sözlü içeriğe sahip ve belirli bir dilde dilsel çeşitliliği yansıtabilen BNC [British National Corpus) benzeri genel derlemler (general corpora); Guangzhou Petroleum English Corpus gibi petrokimya derlemi ya da The HKUST Computer Science gibi bilgisayar bilimleri derlemi benzeri özel alan derlemleri (specialized corpora); ... International Corpus of English (ICE) benzeri eş süremli olarak dilsel veriler içeren eş süremli derlemler (synchronic corpora) ...vb. (McEnery vd. 2006).

Bugün dilin doğal ortamlarından yazılı ve sözlü olarak derlenen verilerle kendine özgü kuram ve uygulamalarla ortaya koyulan sağlam kuruluşlu derlemler, özellikle dil öğrenimi ve öğretimi alanında sezgisel örnekçelerden ve ikincil verilerden yalıtılmış 'gerçek zamanlı' dilsel verileri içermesi bakımından dil çalışmalarına büyük katkılar sağlamaktadır.

Bu projeyle, 8.639 .522 (+/-) sözcükbirim ve 1.089 çeşitli türden 1970-2012 yılları arasını kapsayan çocuk yazını eseriyle bir özel alan derlemi ['Türk Çocuk Yazını Derlemi (TÇYD)] oluşturulmuş ve oluşturulan bu derlem üzerinden 'Türk Çocuk Yazını'nda dil öğretimi açısından öncelikli söz varlığl, çocuk yazını eserlerinin okunabilirlik ve yaşa uygunluk düzeyleri; çocuk yazını türlerinin sözcüksel çeşitlilik ve sözcüksel alan örüntüleri; biçimbirimsel, sözcükbirimsel ve sözdizimsel nitelikleri ile çocuk yazını eserlerinin iç ve dı̧̧ yapısal ögeleri bütüncül olarak ele alınmıştır. 
Bu çerçevede proje ile Türk Çocuk Yazını üzerine yürütülecek ileri düzey uygulamalar doğrultusunda alt araştırma soruları:

- Türk Çocuk Yazını'nda dil öğretimi açısından öncelikli söz varlığı nasıldır?

- Türk Çocuk Yazını'nda eserlerin okunabilirlik düzeyleri nasıldır?

- Türk Çocuk Yazını'nda eserlerin yaşa uygunluk düzeyleri nasıldır?

- Türk Çocuk Yazını'nda sözcüksel çeşitlilik ve sözcüksel alan örüntüleri nasıldır?

- Türk Çocuk Yazını'nda biçimbirimsel, sözcükbirimsel ve sözdizimsel yapılar nasıldır?

- Türk Çocuk Yazını iç ve dış yapısal ögeler açısından nasıldır? şeklinde belirlenmiştir.

Türkiye Türkçesinde İkili Tekrarlar -Derlem Tabanı Bir Uygulama-

[Destekleyen Kuruluş: Çukurova Üniversitesi BAP Birimi Proje No: EF-2008-BAP-11]

İkileme, dilde "anlamı güçlendirmek için aynı kelimenin tekrarlanması, anlamları birbirine yakın, karşıt olan veya sesleri birbirini andıran sözcüklerin yan yana kullanılması (yavaş yavaş, irili ufakl, aşağl yukarı gibi.)" (Türkçe Sözlük, 2005) olarak tanımlanır. "İkili tekrarlar” ise 'ikilemeler' içerisinde yer alan alt türlerinden biridir. 3.332 sözcükbirim bu niteliğiyle Türkiye Türkçesi'nin (TT) sözvarlığında yazın dilinde farklı işlevlerle kullanılmaktadır.

Türkiye Türkçesinde İkili Tekrarlar -Derlem Tabanlı Bir Uygulama-başlıklı çalışmada 'ikili tekrar'lar Türkiye Türkçesinin yazın dilinin karakteristik ve tipik kullanım ortamlarından derlenmiş bir derlem'den (corpus) bir takım metin işleme yazılımları kullanılarak belirlenmiştir. Bu çerçevede TT'de kullanılan "ikili tekrarlar"'ın tam bir dökümü derlem tabanlı olarak yapılmış, ana dili ve ikinci dil olarak Türkçenin öğretiminde temel söz varlığ "ikili tekrarlar" açısından belirlenmiştir. Bu anlamda, TT'nin yazı dilinde kullanılan "ikili tekrarlar"ın sıklıkları belirlenmiş ve kullanımları ise bir sözlükçe ile ortaya koyulmuştur.

Çalışma üç aşamadan oluşmuştur: $i$. Öncelikle metinler, tarayıcılar aracıllı̆̆yla sayısallaştırılıp optik karakter tanıma (OCR) yazılımları kullanılarak bir derlem oluşturulmuş, ii. Oluşturulan derlem bir veri tabanı uygulaması olan PHPRunner v.4.2 ile sözcükbirimsel olarak sorgulanabilir hâle getirilmiş ve ikili tekrar yapıları Regexbuddy v.2.3.2 yazılımı ile belirlenmiş, iii. Söz konusu ikili tekrar yapıları kullanım sıklıkları göz önüne alınarak bir dizin ve sözlükçe oluşturulmuştur.

Çalışma, alanyazında yinelemeler, ikilemeler $v b$. kavramlaştırmalarla ele alınan yapıların bir alt kategorisi olan ikili tekrarları, 'ana dili ve yabancı dil olarak Türkçenin ögretiminde öncelikli sözcükbirimler' çerçevesinde, metinsel düzlemde bu yapıların kullanımlarını esas alarak derlem tabanlı bir uygulamayla araştırma konusu yapması bakımından alana katkı sağlamayı amaçlamaktadır (Özkan, 2019).

\section{Bir Araștırma}

Bilim Dili Olarak Türkçe: Gözbilim (Oftalmoloji) Terimleri Üzerine Derlem Tabanlı

[Destekleyen Kuruluş: Mersin Üniv. BAP Birimi Proje No: BAP-EF TE (BÖ) 2010-4 A]

Türkçenin bilim dili olurluğu ya da olmazlığı bugüne kadar birçok kez üzerinde tartışılmış bir konudur (Özdemir, 1970; Gökberk, 1974; Kocaman, 1982; Köksal, 1983; Başkan, 1983; Kuleli, 1983; Korkmaz, 2001). Bu noktada bilim dili olmak, bilimsel bilgiyi üretmek olarak değerlendirilmelidir. Böyle bir durumda dil, nesne olarak kendisine bilimsel bilgiyi seçer ve onu üretmekle ilgili devingen bir tutum sergiler. Öte yandan Türkçenin bu anlamda bugüne varıncaya kadar oldukça büyük gelişmeler gösterdiği söylenebilir.

Dilbilimin bir alt dalı olan sözlükbilim, bugün, kendine özgü uygulamalarla, derlem dilbilimin paralelinde bilgisayarlar aracılığıyla daha çok dilsel veriyi daha hızlı ve amaca uygun olarak güvenilir çıtılarla işleyebilmektedir. Sözlükbilim araştırmalarında bilişim teknolojileri 
olmaksızın bir sözlükbilim çalışmasını yürütmek bugün için geçerliliğini yitirmiş yöntemlerle araştırma nesnesine yaklaşmak anlamına gelmektedir.

Bu projenin amacı, gözbilim (oftalmoloji) alanında, alanyazında yer almış Türkçe makale ve yayınlarda kullanılan gözbilim söz varlığının sözlükbilim ve derlem dilbilim uygulamaları çerçevesinde terim dökümünü yapmak ve konunun uzmanlarına terim tercihlerinde önemli bir altyapı olanağı sunmaktır.

Bir "gözbilim derlemi” oluşturmak ve terim kullanımlarında genel eğilimleri belirleyerek genelde Türkçenin özelde gözbiliminin terim eğilimlerini kullanım temelli olarak belirlemek ve gözbilimcilerin terimleri Türkçeleştirirken farkındalıklarını bilimsel temelde arttırmak projenin bu çerçevede temel amacıdır.

Projenin konusu bir özel alan derlemi üzerinden yapılacak gözbilim terimlerinin araştırılmasıdır. Bu çerçevede gözbilim terimleri, gözbilim üzerine yazılmış yayınlarda yer aldığı biçimiyle belirlenmiştir.

Oluşturulan gözbilim derlemi üzerinden inceleme konusu olan gözbilim terimleri, sözbirimleştirme (lemmatizing/lemmatization), sıklık (frequency), bağımlı dizin çıkarımı (concordance), eşdizimli kullanımlar (collocations) vb. açılardan araştırma konusu yapılmıştır.

Projeyle elde edilen sözlükbirimsel bulgular ise şöyledir:

- Gözbilim terimlerinde tutarsız bir kullanımın varlığı tespit edilmiştir. Yaygın kullanıldığı gözlemlenen terimlerin ikili kullanımlarının/yazımlarının varlı̆̆ 1 terim kullanımında bir birliğin olmadığının göstergesi olarak değerlendirilebilir.

- Projeyle ulaşılan diğer bir önemli bulgu ise Türkçe veya Türkçeleşmiş sözcükbirimlerin gözbilim terimi olarak kullanımıdır.

- Birlikte kullanım ve eşdizim örnekleri ise proje sorgu sayfasından kullanıcıların erişimine sunulmuştur (http://derlem.mersin.edu.tr/gozbilim/)

- Gözbilim terimi olarak derlemden belirlenen kısaltmalar listelenmiştir.

- Gözbilim terimi olarak derlemden belirlenen sözcükbirimler listelenmiştir.

Türk Yazın Dilinde Argo -Derlem Tabanlı Bir Uygulama-

[Destekleyen Kuruluş: Çukurova Üniversitesi BAP Birimi Proje No: EF-2009-BAP-21]

Bu araştırmaya kadar Türkiye Türkçesi üzerine yürütülen çalışmalarda argonun yazın dilinde kullanımlarını belirlemeye yönelik bir çalışma yapılmadığı görülmektedir. Söz varlığı olarak argonun kullanımı üzerine yapılan çalışmalarda genellikle argonun kaynakları, var olan söz varlığının bu kaynaklara göre sınıflandırması vb. üzerinde durulmuştur.

Önceki çalışmalarda kısmen de olsa edebiyatta "argo" kullanımlarına değinilmiştir. Yazın dilinde argo, komik durum yaratmak, yergi ve gülmece unsurlarına yer vermenin yanında dış dünyanın gerçekliğini kurmacaya aktarmak, gerçekliğe uygun bir kurmaca yaratmak ve dilsel kullanımlarda yeni imge ve biçem yaratmak gibi işlevler üstlenir bir görüntü ortaya koymaktadır (Kefeli, 2002: 170).

$\mathrm{Bu}$ araştırmada ise “Türkiye Türkçesi Yazın Dili”nde kullanılan ve argo sözlüklerinde tanımlı söz varlığını derlem tabanlı bir uygulama çerçevesinde kullanım temelli olarak belirlemek amaçlanmıştır.

Veriye dayalı çalışmalardan olan derlem tabanlı uygulamaların güçlüğü, verinin yoğunluğu olarak karşımıza çıkar. 15 milyon sözcükbirim içeren bir derlemden sorgulamalarla belirli bir söz varlığını ortaya koymak uzun zaman alan bir süreçtir. $\mathrm{Bu}$ nedenle örnekleme yoluna gidilerek çalışmada argo sözlüğünde (Aktunç, 2008) A maddebaşında yer alan argo tanımlı sözcükbirimler 
değerlendirilmiş ve bu anlamda yazın dilinde var olan kullanımların bir dökümü yapılmış ve yazın dili üzerinden kurmaca metinlerde gerçekliği sağlama işlevi olarak argo söz varlığının kullanımları üzerinde durulmuştur.

Bu çalışma üzerinde birtakım araştırmaların da yürütüldüğ $\ddot{~ y a z ı l l, ~ e s ̧ ~ s u ̈ r e m l i ~ v e ~ k ı s m e n ~}$ genel bir derlem olan TD-1 [Türkçe Derlem-1] ile yazın diline ait önceden tespit edilmiş 230 eserin eklenmesiyle oluşturulan bir derlem üzerinden yürütülmüştür. TD-1'e ek olarak Türk Yazın Dili’ne ait 230 eser OCR yazılımları aracılığıyla sayısallaştırılmış, MySql veri tabanı için işaretlemeler yapılmış, sözcükbirimsel olarak PHP arayüzüyle sorgulanabilir hâle getirilen veri işleme aşamaları kurulan bir sistem üzerinden yürütülmüş̧ür.

Oluşturulan bu araştırma derleminde toplam 421 eser yer almaktadır. Eserlerden 18'i dilsel çeşitliliği arttırmak amacıyla çeşitli türlerde antoloji niteliğinde eserlerden seçilmiştir. Bu eserlerin: 95'i roman; 7'si antoloji niteliğinde olmak üzere 68'i şiir; 3'ü antoloji niteliğinde olmak üzere 44'ü deneme-eleştiri; 4'ü antoloji niteliğinde olmak üzere 49'u öykü; 1'i antoloji niteliğinde olmak üzere 35'i tiyatro; 21'i anı; 20'si inceleme-araştırma; 14'ü mizah; 1'i antoloji niteliğinde olmak üzere 18'i sohbet-söyleşi-makale; 1'i antoloji niteliğinde olmak üzere 10'u gezi; 1'i antoloji niteliğinde olmak üzere 4'ü mektup; 4'ü biyografi, 1 'i günlüktür. Ayrıca çeşitli türlerde (efsane, masal vb.) 30 eserle derlem zenginleştirilmiş̧ir.

Sonuç olarak bu çalışmayla toplam 167 yazarımızın 276 eserinde 116 farklı argo söz/deyim/ifade, oluşturulan araştırma derleminden belirlenmiştir.

\section{Gerçek Yaşam Temelli Okul Sözlüğü Uygulamaları}

[Destekleyen Kuruluş: Tübitak-Sobag Proje No: 118K109]

Projenin amac1, yeni, özgün ve gerçek yaşam temelli bir okul sözlüğünü eğitim/öğretim materyali olarak ortaya koymaktır. Bu amaçla, ilkokuldan başlayarak liseye kadar devam eden eğitim-öğretim sürecinde çocukların karşılaşabilecekleri MEB onaylı ve kullanımda olan ders kitapları, çocuk edebiyatı ürünleri, süreli çocuk yayınları vb. doğal dil ortamlarına ait metinlerin yer aldığı özel amaçlı bir derlem (corpus) oluşturulmuştur. Bu derlem üzerinden projenin ana hedefi olan Gerçek Yaşam Temelli Okul Sözlüğü (GYTOS) ortaya koyulacaktır.

Proje, Türkiye Yeterlilikler Çerçevesinde (TYÇ) belirtilen yetkinliklerin geliştirilmesinde tüm eğitim/öğretim ortamlarında formel ve informel öğrenmeye yönelik bir araştırma projesi olma niteliğindedir. Temel araştırma sorusu, Okul çă̆ındaki çocukların (öğrencilerin) karşı karşıya kaldıkları dilsel ortamların söz varlı̆̆ nasıldır? şeklinde ifade edilebilir. Başlı başına bir ARGE boyutuna sahip olan sözlükbilim uygulamaları temelinde okul çağ 1 çocuklarının karşılaştıkları doğal dil ortamlarına ait söz varlığı bir derlem üzerinden deneysel olarak belirlenecektir.

$\mathrm{Bu}$ çerçevede projenin alt araştırma soruları:

- MEB onaylı ders kitaplarının söz varlı̆̆ı nasıldır?

- Çocuğun karşı karşıya kaldığı doğal dil ortamlarının söz varlığı nasıldır?

- GYTOS'nin etkililiği ve çocuğun söz varliğına katkısı nasıldır? şeklindedir.

Projede uygulanacak yöntemle koşut olarak ulaşılması beklenen hedef, eğitim/öğretim materyali olarak bilişim teknolojileri temelli gerçek yaşam temelli okul sözlü̆ğ̈̈ oluşturmaktır. Alanyazında derlem tabanlı (corpus-based) bir okul sözlüğünün eksikliği ve halihazırda var olan sözlüklerin ana dilin kullanıcılarının sezgilerine dayalı, geçerliliğini yitirmiş/geleneksel yöntemlerle seçilmiş sözlük girdilerini içeriyor olması söz konusu sözlüklerin deneysellikten uzak bir yaklaşımla hazırlandığı anlamına gelmektedir. Bu çerçevede, çağrı programının amaç ve hedefleriyle tümüyle örtüşen Gerçek Yaşam Temelli Okul Sözlü̆ğ̈̈ (GYTOS) bir eğitim/öğretim materyali olarak bugüne kadar eksikliği hissedilen önemli bir ihtiyacı karşılama özelliğine sahiptir. 
Derlem dilbilim (corpus linguistics), bilindiği gibi özellikle sözlükbilim (lexicography) çalışmalarında, dilin doğal kullanım ortamlarından seçilmiş metinler aracılığıyla gerçek zamanlı ve deneysel çıktılar sunabilen bir disiplindir. Bu niteliğiyle, projede uygulanacak olan yöntem, özgün ve gerçek yaşam temelli bir okul sözlügünün oluşturulmasında en uygun ve güncel olanakları araştırmacılara sunma gücüne sahiptir.

Öte yandan proje ekibi ve personeli projenin amaç ve hedeflerine uygun olarak disiplinler arası bir niteliğe sahiptir. Proje ekibinde, dilbilimciler, sözlükbilim uzmanları, eğitim bilimciler, Türkçe uzmanları, yazılım uzmanı, alan öğretmenleri, grafik tasarımcısı gibi farklı disiplinlerden araştırmacı ve personel yer almaktadır. Ayrıca önerilen proje, GYTOS'nin oluşturulma süreci, alan eğitmenleri, öğrenciler ve dilbilim/sözlükbilim uzmanları gibi tüm paydaşların katılımını öngörmektedir.

Çalışmada derlem dilbilim ve sözlükbilimin ilke ve yöntemleri ana yapıyı oluşturmaktadır. Öte yandan araştırmacıların süreçte "sistematik hata" yapmalarının önüne geçmek (Maxwell, 1996) ve bilimsel sonuçları keskinleştirmek amacıyla birden fazla veri toplama yöntem ve tekniğinin (odak grup görüşmesi, anket, yarı deneysel bir uygulama, basit uyum indeksi vb.) kullanıldığı, her biri araştırmanın farklı boyutlarının bilimselliğine katkıda bulunacak olan triangülasyon yaklaşımı benimsenmiştir.

Gerek oluşturulma gerekse yayılım/dağılım ve değerlendirme süreçleri açısından GYTOS, metodolojik olarak yenilikçi, çağdaş ve bugün için eğitim/öğretim ortamlarında eksikliği duyulan deneysel sonuçlara dayalı bir eğitim/öğretim materyali olma niteliğiyle özgün bir araştırma projesi olarak alanyazında yerini almıştır.

Projenin ana çıktısı olarak oluşturulacak GYTOS, tüm dijital platformlarda (internet, akıllı tahta, tablet, akıllı telefon vb.) bir eğitim/öğretim materyali olarak kullanıcıların erişimine açılacaktır. Ayrıca devam çalışmalarında önemli bir veri işleme altyapısı olanağını da sunacak olan projenin Türkçe sözlükbilim çalışmalarında yöntem ve çıktıları bakımından örnek bir çalışma olacağı da öngörülmektedir.

\section{Sonuç}

İçerikte de yer aldığı üzere bugüne kadar derlem dilbilim yöntem ve uygulamaları çerçevesinde 11.320 sözlükbirimsel sıfat; 6.441 sözlükbirimsel fiilin derlem denetimi ve derlem tabanlı sözlüğü ile fiilimsilerin kullanımları oluşturulan derlemler üzerinden araştırma konusu yapılmıştır. Araştırma konusu yapılan ana eksenin son halkasını ise hâlen devam etmekte olan Türkiye Türkçesinde sözlükbirimsel adlar oluşturmaktadır. Öte yandan birtakım özel alan derlemleri aracılığıyla çocuk yazını ve göz bilimi (oftalmoloji) alanının söz varlığı belirlenmiştir. Buna ek olarak Türkçede ikili tekrarlar ve argo söz varlığı da derleme dayalı çalışmalarla bugün için ortaya koyulmuş söz varlığı unsurları olarak alanyazında yerini almıştır.

Özetle, derlemler üzerinden Türkçede belirteçler, fiiller, sıfatlar ve adlar, fiilimsiler birer sözcük türü olarak ortaya koyulmuş, çocuk yazınımızın söz varlığı ve gözbilim terimleri ilgili yöntemle açıklığa kavuşturulmuş, argo söz varlığı ve ikili tekrar yapıları Türkçedeki kullanımları açısından belirlenmiştir. Ayrıca yaklaşık 35.000 sözlükbirim içeren Gerçek Yaşam Temelli Okul Sözlüğ̈̈ Uygulamaları (devam etmekte) ortaya koyulmuştur. 


\section{Kaynakça}

Aktunç, H. (2008). Büyük argo sözlük. Ankara. YKY Yayınları.

Başkan, Ö. (1974). Terimlerde özleşme sorunu, Türk Dili Araştırmaları Yıllığı: Belleten, Ankara, TDK Yayınlar1.

Gökberk, M. (1974). Tarihsel arka planı bakımından cumhuriyet döneminde bilim dili, Türk Dili Dergisi, 272: 383-400.

http://turkcederlem.mersin.edu.tr/ ET: 01.02.2020

http://derlem.mersin.edu.tr/gozbilim/ ET: 01.02.2020

http://turkcederlem.mersin.edu.tr/esdizim/ ET: 01.02.2020

http://turkcederlem.mersin.edu.tr/fiilimsi/ ET: 01.02.2020

http://turkcederlem.mersin.edu.tr/fiiller/ ET: 01.02.2020

http://turkcederlem.mersin.edu.tr/okulsozluk/ ET: 01.02.2020

Kefeli, E. (2002). Edebiyat argo ilişkisi. E. Gürsoy-Naskali ve G. Sağol Editör, Türk kültüründe argo içinde. Haarlem, Hollanda.

Kocaman, A. (1982). Bilim dili üzerine düşünceler. Türk Dili Dergisi, 364: 708-709.

Korkmaz, Z. (2001). Bilim dili ve Türkçe. Türk Dili Dergisi, 364: 198-201.

Köksal, A. (1983). Bilim dili, Türk Dili Dergisi, 219: 248-251.

Kuleli, Ömer (1983), Bilim dili Türkçe, Türk Dili Dergisi, 374: 68-72.

Maxwell, K. (2006). A new word is born: how do new words make it into dictionaries? MED Magazine, S: 38.

McEnery, T., vd. (2006). Corpus-based language studies an advanced resource book. New York: Routledge.

Özdemir, E. (1970). Öz Türkçe: bilim dili, Türk Dili Dergisi, 224: 149-152.

Özkan B. (2013). Yöntem ve uygulama açısından 'Türkiye Türkçesi söz varlığının derlem tabanlı sözlüğ̈̈', bilig, Say1: 66. Yaz 2013. 149-178. https://doi.org/10.12995/bilig.2013.6607

Özkan, B vd. (2014). Türkçe üzerine derlem dilbilim uygulamalarl. Karahan Kitabevi. Adana.

Özkan, B. (2010). Türkiye Türkçesinde ikili tekrarlar -derlem tabanlı bir uygulama-. Çukurova Üniversitesi Bap Birimi, EF-2008-BAP-11 Numaralı Araştırma Projesi, Adana.

Özkan, B. (2011). Bilim dili olarak Türkçe: gözbilim terimleri üzerine derlem tabanlı bir araştırma. Mersin Üniversitesi Bap Birimi, BAP-EF TE (BÖ) 2010-4 A Numaralı Araştırma Projesi, Mersin.

Özkan, B. (2011). Türkiye Türkçesinde belirteçlerle fiillerin birlikte kullanılması ve eş dizimlilikleri. Ankara: TDK Yayınlar1: 1031.

Özkan, B. (2012). Türkiye Türkçesi söz varlığında sıfatların eşdizimliliği -derlem tabanlı bir uygulama-. Ulusal Araştırma Projesi, TÜBITTAK-SOBAG-109K104, Mersin.

Özkan, B. (2019). Türkiye Türkçesinde ikili tekrarlar - derlem tabanlı bir uygulama-. PegamA Yayınlar1. Ankara. https://doi.org/10.14527/9786052418888

Türkçe Sözlük, 2005 ve 2011. TDK Yayınları. 